\title{
CONDENADOS PELO DESEJO? Razões de Estado na África do Sul*
}

\section{Laura Moutinho}

\section{Introdução}

O objetivo deste trabalho é analisar a inter-relação entre "raça", ${ }^{1}$ gênero e erotismo na África do Sul, a partir da discussão de dois casos perfilados na Law Report e enquadrados na Immorality Act lei que proibia intercurso carnal "inter-racial", decretada em 1927 e que recebeu em 1950 (início da

* A presente análise foi apresentada no XXVII Encontro Anual da Anpocs, no GT "Raça e Etnicidade", coordenado por Livio Sansone (UFBA) e Marcia Lima (USP/Cebrap) em outubro de 2003, CaxambuMG. O texto é parte da reflexão que desenvolvi em minha tese (Moutinho, 2001), sob orientação do professor Peter Fry, no PPGSA/IFCS/UFRJ. Na tese analisei os valores e as representações sociais sobre "raça", mestiçagem, gênero e erotismo que sustentavam um elo afetivo-sexual entre casais heterossexuais de "raças" diferentes nesses dois países.

Artigo recebido em Novembro/2003

Aprovado em Agosto/2004 era do apartheid) uma nova emenda, que concedia ao Estado maior poder de vigilância e controle sobre os relacionamentos afetivo-sexuais "inter-raciais". ${ }^{2}$ Meu objetivo é ajustar o foco para a percepção de "raça" que preside esse empreendimento, assim como dar visibilidade à importância das assimetrias de gênero e sexualidade na sua construção.

Ao contrário da "etiqueta racial" brasileira, que impôs na esfera pública e política certo silêncio sobre as relações afetivo-sexuais "heterocrômicas", ${ }^{3}$ na África do Sul tais relacionamentos foram regulados (e organizados) explicitamente mediante uma legislação específica, constituída sob a lógica de uma razão de Estado. As idéias sobre separação e "mistura", assim como a própria construção da alteridade "racial" tiveram, no Brasil e na África do Sul, em um certo âmbito, tratamentos absolutamente diferenciados. A valorização do contato e da "mistura" no eixo das representações sociais no Brasil não exclui, entretanto, no interior dessa mesma esfera, a "separação" - a própria tendên- 
cia endogâmica da seletividade conjugal brasileira, evidenciada pelos dados estatísticos, ${ }^{5}$ anuncia que devemos qualificar o que se costuma nomear indistintamente de "mistura" e "contato", procedimento também necessário para analisarmos a questão na África do Sul.

É certo que a África do Sul ajustou seu foco para a "separação", que acabou adquirindo contornos legais e criou um dos regimes totalitários mais controvertidos, trágicos e polêmicos do pós-guerra. O que se pretende neste estudo, entretanto, é qualificar a noção de "separação", perscrutando os valores e as representações sociais sobre "raça", gênero e erotismo encenados nos relacionamentos afetivo-sexuais "inter-raciais" sul-africanos, especialmente em alguns que foram tidos como crime pelo Estado. O objetivo desta discussão é, igualmente, tentar surpreender certas frestas e lacunas presentes nas análises sobre a questão no Brasil a partir da comparação com a África do Sul.

$\mathrm{Na}$ literatura sobre o tema no Brasil, foi necessário me basear não só em análises estatísticas, mas também em romances e peças teatrais para que pudesse analisar tanto a importância do casal homem "negro"/mulher "branca" no processo de miscigenação, como o conteúdo tabu que este evocava (cf. Moutinho, 2001, caps. 1 e 3). Na literatura a que tive acesso sobre a questão na África do Sul, deu-se o oposto. A centralidade desse casal na construção da política do apartheid é tão explícita quanto o desejo que a sustenta (e ameaça). Os processo criminais analisados foram lidos, seguindo as sugestões de Chalhoub (1986) e Caulfield (2000), com o objetivo de recuperar os dramas vividos por esses casais e amantes, e observados como um canal de comunicação não apenas de vozes dissonantes da ideologia reinante, mas também como um reflexo que não deve excluir a margem de manobra possível permitida pela lei que os atores (réus, testemunhas e requerentes) criavam em uma situação de controle e opressão extremada. Assim como Maggie (1992) busco compreender os valores e as representações expressos pelos funcionários do direito e aqueles envolvidos nos processos, procurando identificar, concomitantemente, algumas regularidades que dão sentido às narrativas veiculadas.

\section{"Raça", gênero e sexualidade na era pré-apartbeid}

Para entendermos alguns dos valores e as representações sociais sobre "raça", gênero e sexualidade que mobilizaram a opinião pública no interior de um específico quadro político e social, seguiremos a análise de Jonathan Hyslop (1995) sobre o uso político do debate que precedeu a era do apartheid, na década de 1930, a respeito da criação de uma legislação específica contra os casais "inter-raciais", e os estudos de Saul Dubow (1995) sobre as Comissões criadas com o objetivo de implementá-la. ${ }^{6}$ Tal percurso se mostra necessário por evidenciar, a partir de uma certa chave interpretativa, a centralidade dos relacionamentos afetivo-sexuais "inter-raciais" na manutenção das hierarquias de classe e gênero e do lugar e importância da ameaça coloured (ou da miscigenação) na imaginação africâner, e na posterior instalação legal do apartheid.?

Saul Dubow (1995) destaca que, em termos populares, o impacto das idéias eugênicas tão em voga naquele momento ${ }^{8}$ pode ser medido pelo "horror" da "fusão racial" e da "miscigenação". As relações sexuais "inter-raciais" eram vistas como uma ameaça ao "orgulho" e à "pureza" "raciais", resultando no "declínio" da civilização "branca". O medo da "mistura racial" diz respeito diretamente aos "brancos", ansiosos por sua vulnerabilidade em face da "vigorosa" e "viril" massa de africanos que diziam estar invadindo as cidades na década de $1920 .{ }^{10}$ Além disso, o "perigo negro" foi expresso em termos da ameaça que o homem "negro" representava para a pureza da mulher "branca". Assim, "It is therefore no coincidence that words such as 'virile' and 'vigorous' transposed eugenic notion of fertility with deeply embedded fears of black sensuosness and sexual rapacity" (Idem, p. 181). A lei que proibia casamentos "mistos" (Mixed Marriges Act, decretada em 1949) foi para esses autores, talvez mais que qualquer outra, a que simbolizou o regime do Apartheid.

A importância e a ameaça que a miscigenação representava podem, ainda, ser inferidas a partir do debate que precedeu à Mixed Marriages Act. Já em 1927 fora decretada a Immorality Act, que proi- 
bia o intercurso carnal entre "brancos" e "não-brancos" fora do casamento - as categorias utilizadas na lei para classificar as pessoas eram: european e non-europeans. Um projeto de lei proibindo casamentos mistos existiu, mas não chegou a ser promulgado. Dubow acredita que, naquele momento, provavelmente a opinião pública e o ostracismo social já fossem suficientes para evitá-los, mas esta oposição não representava, para os ideólogos da pureza racial bôer, garantia suficiente. Em resumo, a manutenção do debate e as novas incursões de seus opositores demonstram que eles não eram suficientes o bastante, pelo menos, para conter sua ameaça simbólica. Ameaças, estas, fomentadas pela urbanização, industrialização, empobrecimento da população africâner e formação de um proletariado "negro", que veio se constituindo ao longo desta década e das seguintes.

Em 1936 e 1937 foram feitas novas tentativas para incluir na Immorality Act os casamentos "inter-raciais" de "brancos" com "não-brancos", mas esses projetos de lei não foram adiante. Em vez disso, criaram, em 1937 e 1939, duas comissões governamentais de inquérito para rever o problema, que, entretanto, mantiveram os casamentos "inter-raciais" fora do arbítrio legal. Dubow destaca, porém, que a proibição dos casamentos mistos foi decretada com um caráter de urgência sem precedentes, após as eleições de 1948. Diz o autor:

Members of the governing party were particularly insistent on the need to preserve "race purity". They stressed the aversion on the part of the all races to blood mixture and claimed that the progeny of mixed marriage were social outcast, if not actually of an "inferior type" (1995, p. 182).

Assim, temos a Mixed Marriage Act, em 1949, e a Immorality Amendment Act, decretada em 1950 - ou seja, trata-se da lei decretada em 1927, com uma nova emenda.

Esse debate possui um outro aspecto que interessa diretamente a este trabalho: a definição da categoria coloured. O estreitamento das clivagens por "raça" nas primeiras décadas do século XX, aliado às discussões científicas da época, impuseram uma melhor definição da categoria coloured, que era de difícil definição em termos essencialistas por conta de seu caráter marginal e residual. ${ }^{11} \mathrm{O}$ resultado foi sua alocação em uma zona intermediária - tanto em termos "racial" como social e político - entre "brancos" e "negros". Segundo a definição da Wilcocks Commission de 1937 sobre a população coloured do Cabo, apresentada por Dubow, um "típico" coloured é: "[...] a person living in the Union of South Africa, who does not belong to one of its aboriginal races, but in whom the presence of coloured blood [...] can be established with at least reasoble certainy" (apud Dubow, 1995, p. 186).

Razoável incerteza é o que encontramos nesta definição. ${ }^{12}$ Para Dubow, o problema consiste nas dificuldades da própria comissão para determinar a importância da herança biológica: Os $\mathrm{CO}^{-}$ loureds eram degenerados, ou estavam em processo de "aperfeiçoamento"? Além disso, apesar de considerarem, por um lado, os coloureds menos robustos, com menos resistência, com altos índices de mortalidade infantil e baixa expectativa de vida, por outro lado, eles não tinham certeza se as causas poderiam ser atribuídas à herança biológica ou às próprias condições sociais. ${ }^{13}$ Além disso, a Commission on Mixed Marriage, de 1939, não apresentou unanimidade acerca dos "riscos genéticos da miscigenação", por conta da ausência de provas científicas sobre o caso. Como o próprio Dubow argumenta, entretanto, os estereótipos populares sobre a miscigenação física e moral dos coloureds povoavam a imaginação popular.

Como será visto a seguir, Malan ${ }^{14}$ e seus correligionários mobilizaram politicamente tais representações, considerando que o governo falhou em introduzir uma legislação específica contra os casamentos "inter-raciais" e procuraram capitalizar essa falha nas eleições seguintes. Aquilo que Malan e seu partido consideraram uma "falha" do governo, talvez signifique, entretanto, algo mais. Em outras palavras, nas duas década anteriores ao apartheid, e no interior do próprio governo, parece haver discrepâncias quanto não somente à necessidade de uma legislação específica contra os casamentos "inter-raciais", mas também aos valores "raciais" e de gênero que esta engendra no pensamento africâner.

A mobilização em torno desses valores adquiriu, entretanto, uma substantiva força na arena 
política, sendo bem capitalizada por Malan. Jonathan Hyslop (1995) argumenta que o eleitorado sul-africano "branco" (leia-se africâner) estava, nas eleições de 1938, mobilizado pela imagem da mulher "branca". Vejamos em que termos esta mobilização se constituiu.

Um cartaz distribuído pelo National Party e analisado pelo autor evidencia os sentidos por meio dos quais esta imagem foi veiculada. No centro do pôster vê-se uma mulher "branca" e a seguinte frase em africaans: "A esperança da África do Sul fala para você e diz: Vote no Partido Nacional e proteja meu povo (volk) e minha posteridade". Logo abaixo duas figuras identificam o perigo. À esquerda, uma mulher "branca" pobre aparece sentada na frente de uma casa simples e deteriorada, ao seu lado duas crianças - uma menina "branca" e um menino "negro" - brincam, e em pé, no outro lado da porta, vê-se um homem "negro" com um charuto na mão e um jeito de malandro. As legendas dizem: "The 'hope of South-Africa' is to be protected against 'Mixed Marriage which the United Party Will not Prohibit By Law".

O quadro ao lado traz as demais figuras que ameaçam a mulher "branca" africâner e a própria nação: quatro homens elegantemente vestidos possuem grifados nas pernas das calças as identificações: capitalista, comunista, imperialista e judeu [!]. De acordo com Hyslop:

The caption tells the reader that they represent the peril of "Fusion with Foreign Elements The Price of the United Party's Creed os Love and Peace". In this Hitlerian paranoid fantasy, the Afrikaner volk is warned of an unholy alliance of external forces against it. As in Nazi propaganda, the anti-semitic element is a crucial one, for it provides GNP leaders with a basis for the inherently implausible idea of a capitalist-communist alliance, by suggesting that both groups are arms of a jewish conspiracy. The term "fusion" is a play on the name given to the HertzogSmuts alliance; it is not merely a fusion between two political parties, but a fusion of renegade Afrikaners with the enemies of the volk..$^{15}$

It was not the anti-semitism of the third picture, but rather the portrayal os mixed marriages in the second that became the central issue of the election campaign (Hyslop, 1995, pp. 58-59).
Para Hyslop, os historiadores, e mesmo críticos literários como Coetzee, equivocam-se ao tentar explicar o apatheid sem considerar adequadamente as relações de gênero que a ele subjazem. Mais que uma questão de subordinação de classe e/ou "raça", ou mesmo de "loucura", a emergência do nacionalismo africâner "was the organization of a new form of the domination of Afrikaner men over Afrikaner Women. Male Afrikaner political leaders' behaviour is in fact quite explicable if examined from the perspective of gender relations", defende o autor (Idem, p. 60).

$\mathrm{Na}$ sua perspectiva, as mudanças sociais e econômicas das décadas de 1920 e 1930 trouxeram para o centro da cena a mulher africâner proletária, cuja independência ameaçou as relações patriarcais da sociedade "branca". Ao longo desse período, a sociedade sul-africana assistiu a jovens mulheres "brancas" se dirigirem para as fábricas. Algo que, concomitantemente com a urbanização e a industrialização, ameaçou a forma paternalista de dominação "racial", própria de uma ordem social baseada em uma estrutura agrária.

A "histeria" em torno da proibição dos casamentos "inter-raciais" foi, na perspectiva de Hyslop, um empreendimento dos homens africâneres no sentido de tentarem restabelecer as hierarquias de gênero - aspecto que se coaduna com as idéias de Geoffrey Cronjé. ${ }^{16}$ Ao desenhar a mulher africâner como vulnerável ao homem "negro" e/ou coloured, os homens africâneres se delegavam o papel de protetores da mulher "branca", visando a restabelecer o controle patriarcal. Ao retomar em perspectiva os interesses de gênero, o autor procura dar inteligibilidade ao comportamento político e social da era pré-apartheid, assim como explicitar as bases de sua sustentação.

Nessa linha interpretativa, o eixo da mobilização e da difusão do apartheid africâner centra-se no impacto das mudanças sociais testemunhadas nos anos de 1930 e 1940, que concederam um novo lugar à mulher "branca" no mercado de trabalho e na família. Nas palavras do autor:

During the 1920s and 1930s, the declining hold poorer Afrikaner farmers, smallholders and tenants on the land created a strong trend toward urbani- 
zation. In this period secondary industry was growing in South Africa, and this offered the possibility of employment for young Afrikaners moving off the land [...]. But this process had a particular gender and racial dynamic. In $1924,48 \%$ of the total manufacturing workforce in Johannesburg were white women, and this figure had risen by 1935 to an astonishing 73\% (Idem, pp. 61-62).

Nesse sentido, tais mudanças ecoaram como uma forte ameaça ao domínio "branco" e à própria forma de organização patriarcal. A maior parte dessas mulheres era egressa dos campos e não possuía, na cidade, parentes que pudessem recebê-las. Na verdade, na perspectiva dessa análise e de outras citadas por Hyslop, a moradia era um problema candente para a classe trabalhadora "branca" na África do Sul, especialmente nos complexos industriais e nas grandes cidades. Com o objetivo de "salvar" a classe trabalhadora dos principais perigos que a ameaçavam - a miscigenação e a perda dos laços familiares, dadas pela coabitação entre diferentes "raças" - foi realizada uma ampla reforma residencial de modo a retirar os trabalhadores das áreas faveladas e "mistas". ${ }^{17}$

A ameaça, entretanto, da "degradação sexual feminina" (female sexual degradation) permaneceu, visto que a política de resgatá-las da pobreza e das áreas miscigenadas esbarrou no fato de que a política estava voltada para as famílias pobres, mas as mulheres eram sozinhas. Organizações culturais africâneres - tais como a Dutch Reformed Church e Women's Federation - construíram hotéis para as mulheres sozinhas e "providing simultaneosly with 'correct' white racial and Afrikaner ethinic identification" (Idem, p. 64). ${ }^{18}$

Diante do quadro social, político e ideológico exposto até o momento, o leitor deve imaginar que o número de casamentos "inter-raciais" entre homem "negro" (ou "não-brancos", dado que o casamento com "indianos" (indians) era igualmente uma ameaça) com mulher "branca" era, no mínimo, quantitativamente significativo para sustentar tantos medos e despertar tanto sentimento de vulnerabilidade. Esta não é, entretanto, a estatística encontrada: entre 1930 e 1937, a The Villiers Commission mostrou quea estatística atingiu o ponto mais elevado em 1937, quando ocorreram 101 casos de casamentos em que o marido era o elemento mais "claro" do casal, e o ponto mais baixo deu-se em 1934, com 72 casos. Além disso e, surpreendemente, a maioria desses casais era composta de homem "branco" e mulher $\mathrm{CO}^{-}$ loured. Ainda de acordo com Hyslop, o número de casamentos entre mulher "branca" e homens indians ou africans era baixíssimo no período. Vejamos: segundo os dados do relatório da Comissão, entre 1929 e 1931 foram registrados três casos de casamento entre mulheres "brancas" e homens africans e nenbum foi registrado nos cinco anos consecutivos. No mesmo período, foi registrado, em território nacional, o ponto máximo de casamentos entre mulher "branca" e homem indian - oito em 1937 -, e o mais baixo um, em 1935. Assim, por exemplo, tomando o ano de 1937 como base, temos 101 casamentos entre homem "branco" e mulher coloured, para oito entre mulher "branca" e homem indian, e nenbum de mulher "branca" com homens "negros" (cf. Hyslop, 1995).

Vejamos mais alguns fatos: até o momento, seguimos a trajetória fornecida por alguns autores sobre a história sul-africana no período entre 1927 (data do decreto da Immorality Act - a lei que proibia intercurso sexual entre pessoas de "raças" distintas) e 1949 (data do decreto da Mixed Marriage Act, já sob o regime do apartheid), mas esta linearidade temporal é eletiva e não deve obscurecer as polêmicas, os conflitos e as contradições que, calcados nas clivagens de gênero, "raça" e sexualidade, configuraram uma verdadeira arena de disputa pelo poder. Além disso, as questões que mobilizaram o governo no sentido de decretar as duas leis não estão necessariamente correlacionadas. Hyslop nos ajudará novamente neste ponto.

A Immorality Act, embora se circunscreva às preocupações do governo relativas aos relacionamentos afetivo-sexuais "inter-raciais", visava, mais especificamente, a conter a prática da prostituição. Algo que atingia mais diretamente o casal homem "branco"/mulher african. Como indica Hyslop, e como será visto a seguir, o texto da lei torna crime a relação entre white ou european e africans, não regulando, portanto, as relações en- 
tre "brancos", coloureds e indians, assim como, é preciso reiterar, entre africans e indians.

A questão, aqui, talvez seja a de inquirir sobre que tipo de receio a ideologia do volk africâner mobilizou. Que fatores funcionaram para persuadir seu eleitorado sobre o caráter urgente da necessidade de "proteção" da mulher "branca"? Como vimos, a quantidade em si de casamentos "inter-raciais" não parece ter sido um fator suficientemente forte para mobilizar a sociedade civil de maneira tão "histérica" como apontam os autores, inclusive convencendo-a da implementação de uma legislação que mantivesse as diferentes "raças" separadas, cerca de uma década depois. Em outras palavras, e seguindo a estratégia adotada em relação aos dados e às análises sobre nupcialidade no Brasil e as representações sobre o tema que desenvolvi no doutoramento (Moutinho, 2001), fazse necessário perscrutar com cuidado esta diferença, não só no que ela revela explicitamente, mas também nas entrelinhas e nas frestas de suas contradições.

O caminho e o quadro político-social apresentado por Jonathan Hyslop fornecem parte da solução para o problema, mas os valores e as representações discutidos e analisados por Coetzee (1991) e Fernando Rosa Ribeiro (1994 e 1995) são centrais para nossa compreensão dos valores e das representações mobilizados pela ideologia (separatista) do volk africâner. Nesse ponto, porém, talvez devêssemos seguir a análise de Verena Stolcke (1992), que ressalta que na sociedade cubana do período colonial o controle masculino da pureza sexual e "racial" da mulheres "brancas" foi resultado do seu papel central na reprodução das assimetrias sociais, cujo elemento distintivo era a "pureza da raça". Como a própria autora adianta, as relações entre os sexos transformamse em constructos dotados de significados sociopolíticos expressos nas hierarquias entre os gêneros, e na sua inter-relação com os sistemas de parentesco, de modo que às mulheres "brancas" cabe o papel de mediadoras entre a pureza "racial" da família e a conseqüente manutenção do status social diferenciado. Creio que assim como no Brasil, o casamento "inter-racial" pensado na relação homem "negro"/mulher "branca" se reves- te como poluidor por representar uma ameaça ao sistema branco patriarcal. A ação do Estado na África do Sul após a instalação do apartheid, entretanto, evidenciou uma lógica de pureza "racial" operada pelos ideólogos africâneres, no qual o próprio desejo "inter-racial" precisava ser "neutralizado", para usar uma expressão de Coetzee.

Vejamos, a seguir, como, no interior desse quadro social, os relacionamentos afetivo-sexuais "inter-raciais", articulados às assimetrias de gênero e "raça", aparecem no texto da lei.

\section{Condenados pelo desejo? "Raça", gênero e erotismo na Immorality Act}

No modelo mediterrâneo de "honra e vergonha", ao qual o Brasil aparece freqüentemente referido, a relação entre homens e mulheres está baseada no que se costuma nomear de "duplo padrão de moralidade". Enquanto os homens gozam de ampla permissividade sexual, as mulheres são controladas por uma rígida moral sexual, cuja retidão funciona como o depositário da honra masculina: sob as mulheres recai a vergonha e o controle masculino visando à manutenção da honra familiar. ${ }^{19}$

Os pontos de contato desse modelo com o apresentado por Geoffrey Cronjé, por exemplo, não obscurecem uma diferença fundamental: a presença de um controle sexual/moral sobre o comportamento masculino africâner. No Brasil, como aponta Sérgio Carrara (1996), a regulamentação da prostituição esteve associada à disciplinalização e à moralização do espaço público. Mais do que controlar o comportamento sexual masculino - visto que a prostituição era tida como um "mal necessário por impedir que os imperiosos desejos masculinos atingissem as mulheres 'honestas" -, objetivava-se mantê-las sob a mira da vigilância policial, fora da esfera pública (Idem, p. 166). Na África do Sul, o foco do controle não incidiu apenas sobre a meretriz. As medidas não visavam a regular a prostituição, mas contê-la. Assim, se, por um lado, a defesa moral da mulher "branca" funcionou como um catalisador de medos e ameaças ao volk africâner, por outro, a regulação da conduta sexual (e moral) masculina era 
uma preocupação que assumiu o formato legal com o decreto da Immorality Act em 1927.

O material jurídico levantado na Cidade do Cabo é resultado de um levantamento dos casos enquadrados na Mixed Marriage Act e na Immorality Act, na Law Report no período de 1948 (data da implantação legal do apartheid) a 1985 (data da revogação de ambas as leis). A Law Report traz um resumo de casos importantes que mudaram ou levantaram problemas à jurisprudência, e no período em questão há um total de doze casos casos enquadrados nas citadas leis: um da Mixed Marriage Act, onze na Immorality Act e um digest of cases on appeal. Na presente discussão irei me deter na análise do texto da Immorality Act e de dois casos de apelação de sentença que foram enquadrados nesta lei.

Gostaria de ressaltar, primeiramente, que no texto da Immorality Act as penalidades para aqueles que mantivessem intercurso carnal com outra "raça" eram diferenciadas de acordo com o sexo do indivíduo. Os verbos utilizados para designálos não somente são diferenciados, como também expressam a assimetria entre eles. Nas seções 1 e 2 da lei, vemos que, no caso dos homens europeans ou natives, se praticassem (who has) intercurso carnal estariam sujeitos a uma pena de até cinco anos de prisão. Já as mulheres europeans ou natives que permitissem (who permits) o intercurso carnal com um homem de outra "raça" poderiam ser confinadas por até quatro anos.

É interessante notar como a principal assimetria que o texto da lei explicita é entre os gêneros, tanto nas penalidades diferenciadas, como nos verbos utilizados para designar o ato sexual: os homens aparecem como "ativos" e as mulheres como "passivas". Os verbos utilizados e as penalidades indicam, ainda, que os homens europeans e natives estão, ao menos nesse item, concebidos em uma situação de igualdade. Aspecto que, se por um lado surpreende, em virtude da ênfase concedida por parte da literatura à ameaça que o homem "negro" representava, por outro lado, no arcabouço ideológico do apartheid, tal como concebido por Cronjé, revela a necessidade de controle e regulamentação da conduta sexual dos homens "brancos", posto que a separação era, como já visto, algo extensivo a todas as "raças" igualitariamente. A mesma lógica aplicava-se às mulheres, de modo que, em termos da responsabilidade em "permitir" um ato sexual, a lei também não estabelecia diferença "racial" no interior do gênero feminino.

Além disso, creio que o binômio atividade/passividade, expresso nos verbos utilizados para designar o ato sexual com uma pessoa do sexo oposto, indica ainda que o desejo erótico está alocado nos homens, dado que as mulheres somente "permitem" o ato sexual. O fato de esta lei ter sido decretada como resultado das preocupações governamentais em regulamentar a prostituição poderia, de forma plausível, explicar a ênfase no desejo sexual masculino. O texto da lei, entretanto, veicula, pelas assimetrias assinaladas, alguns sentidos e significados "raciais" que não devem passar despercebidos.

Ao contrário das representações sobre as diferenças "raciais" e de gênero mobilizadas pelos autores que analisaram a dinâmica dos relacionamentos afetivo-sexuais no Brasil, ${ }^{20}$ na África do Sul não encontrei nenhuma referência à "hipersexualização" das mulheres coloureds ou natives e bantus. Ao contrário, o foco esteve sempre ajustado para o comportamento masculino: ou dos "brancos" "miscigenadores inescrupulosos", ou dos coloureds e blacks e sua atração seja pelas mulheres coloureds, como no caso dos primeiros, seja do desejo pelas mulheres "brancas", como no caso dos últimos.

A seção 3 da lei estabelece que poderia pegar até cinco anos de prisão qualquer pessoa que "propusesse" (procures) ou "facilitasse" (in any way assists in bringing about such intercourse) a uma mulher, seja native seja european, o intercurso carnal com um homem de outra "raça". Vemos, assim, que ao arrolar terceiros, a questão deixa de ser algo que diga respeito somente àqueles que incorressem no delito. Com essa medida, creio que tanto se intenciona reprimir aquele que "propõe" - e nesse sentido também a prática da cafetinagem -, como, ao responsabilizar o "facilitador", abre-se a possibilidade de maior vigilância contra os intercursos sexuais "inter-raciais". A certeza da eficácia dessa medida, assim como a coletivização da responsabilidade em se manter a pureza "racial", aparece na pena designada para o 
crime: cinco anos de prisão, tempo idêntico ao do homem que pratica o próprio ato sexual, o que nos remete a algumas da idéias de Cronjé sobre o contato sexual "inter-racial".

Fernando Rosa Ribeiro cita um trecho do livro de Cronjé sobre a miscigenação e os miscigenadores que vale a pena transcrever:

Há brancos, nascidos neste país, que se tornaram tão degenerados em termos de moralidade, respeito próprio e orgulho racial que não sentem nenhuma objeção com relação à miscigenação. Alguns deles contraem casamentos mistos, mas a imensa maioria mistura seu sangue extra-maritalmente. A miscigenação tem de ser caracterizada como crime [...] contra a raça branca [...]. Os brancos têm de proteger-se contra miscigenadores inescrupulosos e criminosos, não somente pela proibição de casamentos mistos, mas também tornando punível todo outro tipo de miscigenação (intercurso ilegal). O indivíduo é responsável perante a sua comunidade por suas ações. A comunidade volk tem o direito de chamar à responsabilidade qualquer um que atente a seu mais alto interesse. É dever da comunidade de volk punir tais atrocidades. O interesse do volk pesa sempre mais que o interesse pessoal (Cronjé apud F. R. Ribeiro, 1994, p. 18, grifos do autor).

A vigilância sobre o comportamento alheio recebe mais incentivo na seção 4 da lei, ao determinar que qualquer "proprietário" ou "ocupante" de imóvel que vier a permitir o uso de sua locação contra as previsões dessa lei também poderá ser preso por até cinco anos.

No momento em que a lei foi decretada, ainda era permitido contrair casamentos "mistos" ( $m i x$ marriage), mas a determinação de restringir a relação sexual ao âmbito das relações formais aparece no item 5 da lei, estabelecendo que "os acusados que fossem casados e pegos em ato julgado ilícito deveriam provar que seu estado civil é de casado".

Outro aspecto interessante, refere-se à assimetria que articula as diferenças entre os sexos e a nacionalidade. Se qualquer pessoa "não nascida" na África do Sul for enquadrada nas seções um, três ou quatro, o ministro do Interior poderia detê-la sob custódia. O interessante, neste caso, é que a seção 1 diz respeito explicitamente aos homens, e as seções 3 e 4 , ainda que não referidas diretamente, também atingem mais o sexo masculino, de modo que as seções nas quais os acusados poderiam ser enquadrados eram, sobretudo, as relativas aos homens estrangeiros que viessem a violar a lei. Por oposição, observa-se que o Estado não estava preocupado com o comportamento das mulheres estrangeiras no país. Creio que tanto se trata de um indício da preservação dos ventres maternos africâneres, por meio de uma medida que visa a proteger as mulheres dos homens estrangeiros de qualquer "raça", como, por oposição, na referida ênfase no controle do comportamento sexual masculino.

Por fim, parece-me interessante que não há no texto da lei qualquer indício sinalizando especial preocupação relativa à preservação da "raça branca", antes, a preocupação primeira parece ser a manutenção das raças separadas. Como veremos analisaremos a seguir, na aplicação da lei a pricipal preocupação parece ser, justamente, a de preservar a pureza "racial" africâner.

Vejamos, a seguir, essas e outras questões em alguns dois processos criminais enquadrados na Immorality Act.

Um processo de criminal law enquadrado na Immorality Act de 1927 com amended, traz mais alguns elementos interessantes à analise. Essa lei, decretada em 1950, define como crime qualquer comportamento entre european e noneuropean que seja considerado de natureza sexual. A questão da classificação "racial" é complexa, pois não encontrei especificações sobre este ponto na emenda anexada à lei, mas nos processos criminais a distinção seguiu european/non-european, concomitantemente com as múltiplas categorias que estas duas agregam, tais como white, bantu, native, coloured. Além disso, na versão anterior, apenas o intercurso sexual era considerado crime. A emenda, que inclui a intenção, parece ampliar a vigilância sobre o ato. No processo em questão, trata-se de uma acusação de intercurso carnal ilícito entre um rapaz european de 23 anos, e uma garota non-european, menor de 16 anos. $^{21}$ 
De acordo com a Immorality Act:

[...] makes it offence for an European male to have ilicit carnal intercourse with a non-European female in circunstances wich did not amount to rape, attempt to commit rape, indecent assault, or a contravention of secs. 2 or 4 of the Girl's and Mentally Defective Women's Protection Act of 1916.

Esta última lei determina que é crime manter relações sexuais com mulheres com menos de 16 anos. Desse modo, os dois foram considerados culpados de acordo com a Immorality Act. A menina classificada como non-european foi condenada por ter permitido que um homem european mantivesse com ela um ato sexual ilícito, e por ser menor de idade perante a lei, foi mandada para um reformatório. Em uma eficiente manobra da defesa, o rapaz, no entanto, acabou sendo absolvido porque a menina - ainda que non-european era menor de 16 anos. Os advogados conseguiram enquadrá-lo na Girl's and Mentally Defective Women's Protection Act, que determina ser crime intercurso sexual com moças menores de idade. Porém, "in regard to accused $n^{\circ} 1$, it seems to me that it is impossible to do anything other than quash the conviction and set aside the sentence. [...] This Court cannot substitute an entirely new charge and then enter a veredict of guilty".

Uma certa hierarquia de gênero articulado à "raça" insinua-se no estabelecimento dos critérios a serem julgados. Se, por um lado, o rapaz não poderia ser condenado por um crime pelo qual não estava sendo acusado, por outro, por que o mesmo procedimento não foi utilizado com relação à menina? Por ser menor de idade perante a lei e ter cometido um "ato imoral", ela acabou enclausurada em um reformatório.

Este caso e o próprio sistema de classificação utilizado - european/non-european - evidenciam que na sua aplicação - do mesmo modo que na Mixed Marriage Act - o objetivo dessas leis não era somente evitar a miscigenação, mas um tipo específico de miscigenação. Pelo que pude depreender, toda uma engenharia social foi montada com base em quatro leis - Mixed Marriage Act, Immorality Act, Group Area Act e Population Registra- tion Act - visando, sobretudo, à manutenção da pureza racial "branca". Ainda que o discurso de Cronjé enfatizasse que a "separação" (apartheid) era algo extensivo a todas as "raças", e que aos africâneres, por sua superioridade biológica e cristã, deveriam ser os "tutores" das "raças" atrasadas, os processo criminais - até mais do que as leis - revelam um movimento de manutenção, sobretudo, da pureza "racial branca".

Como afirmei anteriormente, a emenda acrescentada a esta lei incluía, sobretudo, aspectos que implicavam um aumento da vigilância sobre a intenção de manter intercurso carnal com um indivíduo de outra "raça", ou, em outros termos, e seguindo a sugestão de Coetzee (1991), evoca a vigilância (visando à contenção) do próprio desejo "inter-racial". Vejamos como essa sugestão pode ser apreendida em outro processo de apelação.

O caso em questão é de apelação contra sentença, datada de fevereiro de 1969 e foi enquadrado na Immorality Act 23 of 1967, em Eastern Cape Division. Os acusados são um imigrante "branco" inglês, de 57 anos, que vivia há alguns anos na África do Sul, e uma mulher bantu, sul-africana, de 22 anos, que trabalhava como empregada doméstica na casa deste imigrante. Os acusados apelam contra a condenação de quatro meses de prisão por "conspiração" de ter intercurso carnal ilícito ("conspiring to have unlawful carnal intercourse in contravention").

Na data da ofensa -noite de 14 de junho de 1968 - a esposa do apelante estava na Inglaterra de férias e ele vivia sozinho em sua casa há mais de seis meses. A apelante havia sido contratada como empregada doméstica pelo mesmo período, diz o processo. Uma informação que parece ter por objetivo sugerir um caso amoroso entre os apelantes. A acusada, entretanto, afirmou que todas as noites retornava à sua casa.

Alguns indícios levaram a Corte a supor que os apelantes possuíam um relacionamento de "considerável intimidade" ("a relationship of considerable intimacy"): peças de roupa da acusada foram encontradas no armário do imigrante inglês, ela fazia suas refeições na sala de jantar do apelante (algumas vezes, inclusive, acompanhada por seus amigos), usava o aparelho de som da casa e 
bebia seu licor. Para a Corte, esse relacionamento era, para os padrões de normalidade sul-africanos, excessivamente informal se comparado com o recomendado entre patrão e empregada, de modo que eles acreditaram que ela cuidava da casa como se fosse "sua" durante o trabalho.

Na noite em questão, os apelantes estiveram sozinhos por pelo menos duas horas antes de a polícia ter sido notificada, às 22 horas. Quando a polícia bateu à porta, a luz do quarto estava acesa e foi imediatamente apagada e novamente acesa. A apelante apareceu em uma janela, quando foi presa e levada para a porta da frente para persuadir o apelante a abrir a porta, proferindo a seguinte frase: "Jack, my love, open, it is Victoria, open the door". Quando a porta foi aberta, o apelante estava segurando uma espada em uma posição ameaçadora. A apelante, quando entrou na casa, ligou o aparelho de som e "in a petulant gesture" jogou um cinzeiro na direção do apelante e, em seguida, subiu para pegar seu chinelo no quarto dele. Foi encontrada a bolsa da apelante no quarto do "patrão" e uma das camas estava com os lençóis amassados como se duas pessoas tivessem se deitado nela.

O magistrado rejeitou a versão da defesa de que o apelante teria chegado em casa "affected by liquor" e tinha ido dormir sozinho com seu pequeno cachorro deitado sobre o travesseiro ao lado dele, assim como rejeitou a versão de que a "empregada" também estaria de pileque e que teria ido dormir no chão do quarto livre (e sem camas) até a chegada da polícia. Nesse novo julgamento (trata-se de um caso de apelação), foi considerado irrelevante se a Corte deveria (ou não) julgar que a apelante estava afetada pelo álcool, tendo em vista que sua atitude "indiscreta/descarada" (blatant) era de outra forma inexplicável.

A humanização do animal e a animalização da moça bantu não foram suficientes. A Corte rejeitou a versão dos acusados, mas não pôde provar que eles haviam mantido intercurso carnal ilícito, ou mesmo que tivessem tentado realizá-lo; entretanto, chegaram à conclusão de que eles "were conspiring to do so". Vale a pena transcrever essa parte do processo:
I say that the only inference from their conduct was that each had subjectively reached a decision to have intercourse with the other and that decision of each had been communicated to the other and that being the case the existence of the agreement essential for conspiracy has been clearly demonstrated. The accused were there (at) that time of nigth with a light in the bedroom, both being sober, in circumstances which can lead to no other reasonable inference but that had conspired to have sexual intercourse (grifos meus).

Essa conclusão foi rejeitada na apelação, que considerou as provas apresentadas insuficientes. Para os "conselheiros" que julgaram a apelação, os acusados possuíam um relacionamento muito íntimo, e o "fato" de eles terem ficado sozinhos por algumas horas não indicava necessariamente que eles "intencionavam" manter intercurso carnal sexual. A questão era: "If they intent was sexual, one wonders why they had not yet given effect to it".

Os apelantes, de acordo com a interpretação sobre o caso, tiveram muitas oportunidades de manter relações sexuais regulares, já que possuíam comprovado grau de intimidade. Assim, a presença dos dois e as circunstâncias apresentadas não indicavam que naquela noite, em particular, eles tivessem a "intenção", e como eles estavam sendo acusados por aquela noite (e não por ter um relacionamento íntimo duradouro, mais informal, inclusive, do que o que era considerado normal entre um "branco" sul-africano e sua empregada bantu), os apelantes ganharam a causa. Para os magistrados que julgaram a apelação, o Estado não apresentou provas suficientes de que naquele momento eles tivessem a intenção de manter intercurso carnal. Desse modo, o veredito final foi: "The conduct of the appellants was unwise in the extreme but in my view the State did not establish their guilt beyond reasonable doubt and the appeal should be alloowed".

Ainda que os apelantes tenham ganho a causa, chama atenção a importância da "intenção" no proceso e o próprio debate suscitado. Entre os processos criminais que recolhi, enquadrados na Immorality Act, a maioria apresentava a dificuldade de provar que houve intercurso carnal "inter-racial" 
ilícito - grandes debates se instituiam em torno desse ponto. Entretanto, poucos réus foram inocentados, pois, ainda que o delito não pudesse ser provado, as evidências apresentadas indicavam "intenção". O que significa, nesse contexto, "intenção" senão o próprio desejo sexual?

Nesse sentido, a intenção de "conspirar", ou seja, a manisfestação do desejo sexual "inter-racial" funcionou como uma categoria-chave que visava, por meio do discurso "racial", a manter as hierarquias entre os gêneros, assim como as de classe. Seguindo a sugestão de Coetzee (1991), entretanto, talvez se possa interpretar as condenações imputadas como uma evidência da condenação do próprio desejo "inter-racial". Os próprios termos da lei evidenciam a validade dessa interpretação: a "intenção", ou o próprio desejo sexual "inter-racial", tendo em vista seu caráter escatológico e destruidor, configura-se como uma conspiração contra a "raça branca". Evoca, assim, uma estratégia molecular de ação.

Se, por um lado, a cada grupo "racial" era atribuído uma distinta divisão moral e sexual, por outro, tais distinções precisavam não somente ser objetivas, como também atender às exigências da lei. Os embates políticos e ideológicos, uma vez regulados pelos cânones da lei, abrem diferenciadas possibilidades interpretativas. É próprio do Direito zelar pelo controle da contitucionalidade da lei, assim como por sua execução e interpretação. Desse modo, tanto as ambigüidades identitárias da categoria coloured, como as divisões morais e sexuais correspondentes, deram margem a uma série de avaliações ambíguas e subjetivas, que se constituiu em um espaço de manobra utilizado ora pelos magistrados, ora pelos acusados e requerentes.

$\mathrm{Na}$ imaginação essencialista africâner, OS COloureds eram ameaçadores porque ambíguos. Não se constituíam como uma "raça", posto que não possuíam língua e cultura próprias, e, tendo em vista sua mentalidade profundamente separatista, tampouco poderiam ser classificados no grupo aborígine ou native. Essas características, em contraste com os valores individualistas e modernos que adentravam o país, egressos da industrilização, da urbanização e da influência do racio- nalismo inglês, impunham um quadro social ameaçador, para o qual as correntes eugências lamarckianas e mendelianas não ofereciam solução satisfatória, como no caso do Brasil.

Como apontou Peter Wade em seu estudo sobre a Colômbia (1993), a mestiçagem compreendida como "branqueamento" possui um caráter inclusivo e de, certa forma, até mesmo democrático, posto que incorpora a alteridade à nação. A influência neolamarckiana no Brasil possibilitou, como argumenta Sérgio Carrara, um deslocamento da "raça" para o excesso sexual e a doença, de modo que "eugenizar' significou predominantemente 'sanear"' (1996, p. 129). Este argumento permitia uma leitura positiva sobre as teses da degenerescência, que caracterizavam a idéia de miscigenação. Não se pode perder de vista, entretanto, que a perspectiva do branqueamento possui, concomitantemente, um caráter discriminatório: os "não-brancos", em geral tidos como inferiores, poderiam adquirir traços civilizatórios e elevar-se moral e socialmente por meio do "branqueamento" (cf. Wade, 1993, 2000), uma possibilidade de "limpeza" ou "purificação" nos termos de Mary Douglas, que se mostra inviável no sistema africâner, no qual a "impureza" "racial" era uma marca indelével e destruidora.

No sistema brasileiro, como apontou Peter Fry (1996, 2000), a ideologia da "democracia racial" convive com a ideologia do "racismo": não se pode dizer que uma seja mais "real" do que a outra, tendo em vista que ambas são representações sociais calcadas na "raça", de fato contraditórias, que todavia orientam a ação social. Nesse quadro social, há, em concomitância com o "racismo", a possibilidade de mobilidade (e manobra) social mediante a incorporação de certos signos de status - algo que foi distinguido na literatura que tratou do tema entre o matrimônio formal e o informal, como o concubinato e o amasiamento. Mas, cabe ressaltar, que tal distinção acompanhou a hierarquia entre os gêneros, tendo em vista que, grosso modo, se registra o casal homem "branco"/mulher "mulata" no concubinato e no erotismo; e, ao casal homem "negro"/mulher "branca", recai a possibilidade de casamento formal, ainda que por interesse. A literatura sobre o tema destaca - ain- 
da que muitas vezes de forma sub-reptícia - que se esse homem "negro" compensar o seu status inferior, dado com a aquisição de títulos de prestígio, poderá ser inserido no sistema de trocas e reciprocidade formais.

Os dois elementos estruturadores das relações afetivo-sexuais "inter-raciais" acima destacados desejo-erótico e mobilidade social - estão igualmente presentes nas representações sobre o tema na África do Sul. Entretanto, o sentido conferido opera alguns significados distintos. A mulher "negra/mulata" não aparece no registro do erotismo infrene na fala dos ideólogos do apartheid, e sobre os homens "brancos" (em especial os "miscigenadores inescrupulosos" evocados por Cronjé) impôs-se um específico e rígido sistema de controle. No caso da relação homem "negro"/mulher "branca", o sentido não parece ser o de ascensão social, mas, antes, de confisco e exploração da mulher "branca" africâner.

Os ideológos do apartheid visavam a eliminar qualquer fresta de manobra ou mobilidade existente antes mesmo do regime ter sido instituído, em 1948. Nesse sentido, ainda seguindo o argumento de Fry (1996, 2000), vemos como no Brasil desenha-se um quadro significativamente diferenciado mas igualmente complexo, tendo em vista que as ações públicas e políticas poderiam operar uma prática "racista" concomitante à afirmação da "democracia racial"22

Para finalizar, gostaria de lembrar que, em 1985, a Mixed Marriage Act e a Immorality Act foram revogadas. Os casais "mistos" que se constituíram após a liberação legal poderiam casar legalmente, mas não coabitar, uma vez que a Group Area Act - lei das moradias separadas - somente foi revogada em 1991. Assim, cada um dos cônjuges, ainda que legalmente unidos, precisava viver separado, habitando em sua própria área "racial".

Essa situação gerou uma verdadeira polêmica e inúmeras denúncias ao longo desses seis anos, ao menos nos jornais de língua inglesa a que tive acesso. Sem pretender entrar de forma sistemática na análise desses periódicos, gostaria de ressaltar que, tanto quanto os casais "inter-raciais" e seus problemas relativos à coabitação foram utilizados como símbolo da denúncia do que então se acusava de "mudanças cosméticas" promovidas pelo regime do apartheid, as fotos que ilustravam as reportagens evidenciavam a resistência popular a esse tipo de relação: invariavelmente, as alegres fotos dos casamentos foram tiradas junto à família do cônjuge "não-branco". Em nenhuma das fotografias a que tive acesso a família do cônjuge "branco" estava presente. Além disso, e talvez ainda mais importante, o elemento "branco" do casal era sempre estrangeiro, fosse ele mulher ou homem. O próprio casal símbolo da mudança, o primeiro a ser constituído legalmente após a lei ter sido revogada, era composto de uma mulher "branca" norte-americana e um homem "negro" sul-africano. Somente encontrei casais "inter-raciais", cuja nacionalidade de ambos era sul-africana, entre as escassas reportagens sobre as relações afetivo-sexuais entre gays.

\section{Desejo erótico "inter-racial" na construção da identidade nacional: breve olhar comparativo}

$\mathrm{Na}$ interpretação de Coetzee (1991), o apartheid idealizado por Cronjé, e tendo em vista sua importância na construção de seu aparato legal - o próprio sistema instalado legalmente em 1948 -, foi concebido com o objetivo de interditar ou "neutralizar" o desejo "inter-racial", ou, em outras palavras, como um forma de interdição e "neutralização" do desejo. Em Gilberto Freye (assim como em outros autores do período analisado, excetuando Oliveira Vianna) ${ }^{23}$ temos o desejo explicitado, dito, afirmado; algo particularmente singularizado na obra de Freyre. Porém, ao contrário do autor sulafricano, vemos o desejo "inter-racial" ser o elo que articula alteridades "raciais" de maneira a constituir a própria nação: o livro Casa-grande E senzala funciona como um grande palco, sobretudo por conta da noção de "patriarcalismo poligâmico", que dramatiza o encontro do português libidinoso com a lúbrica "mulata". Em Oliveria Vianna, por sua vez, o desejo em si não está explicitado, mas tampouco é negado: caberia ao próprio Estado promover o "bom desejo", cujo resultado seria a contrução da, igualmente, "boa nação". 
No Brasil, o desejo "inter-racial", e não a "mulata", é o elo que funda a nação. Em outras palavras, trata-se do desejo viabilizado a partir de uma específica hierarquia de gênero e "raça" expressa, particularmente, na relação erótica entre homem "branco" e mulher "mestiça". A realização do desejo, constituído e operado pela máquina colonial (e também nacional), deu-se no caminho que articulou o homem "branco" com a mulher mestiça: um casal que, do ponto de vista das alianças e das reciprocidades de parentesco, não teria uma moeda de troca social para efetuar a transação.

Assim, vemos que o desejo, mas não qualquer um, o desejo "inter-racial", ainda que tematizado e qualificado de maneiras distintas, apresenta-se, tanto na África do Sul como no Brasil, como elementos constituidores da nação. Um pela via da interdição legal, outro pela via da sua institucionalização. Um, expresso pela ameaça que o homem "negro" representava contra a mulher "branca" e, conseqüentemente, contra a própria nação; outro, constituído pelo encontro erótico do homem "branco" (dominador) com a "mulata" (dominada): "raça", gênero e desejo sexual articulados de maneira peculiar.

Em seu instigante trabalho, Rosana Heringer (1995) compara as análises de Araújo (1994) sobre Freyre e de Coetzee (1991) sobre Cronjé. Como aponta a autora, o desejo aparece como um "valor" na análise de Araújo sobre Freyre e como "destruição" na análise de Coetzee, sobre Cronjé. Talvez seja possível acrescentar à percepção de Heringer a idéia de que para ambos os autores o desejo seja um valor, porém, para o primeiro, trata-se de um valor ao qual se articula a realização do erotismo que une "raça", nacionalidades e classes distintas, cerzindo as alteridades e corporificando uma nação; para o segundo, de fato, expressa, dada a possibilidade de articulação desses termos, a destruição.Trata-se de um sentimento de destruição que ao "demonizar" as alteridades "raciais" alimentava fronteiras, desenvolvendo certo sentimento de pertencimento e, também nesse caso, de nação. Nesse sentido, é possível afirmar quenos dois casos, o desejo é o elo fundamental da afirmação, não somente da viabilidade das duas nações onde há (e houve) ampla mesti- çagem, mas também da construção da própria identidade nacional.

Como ponto de contato, encontram-se em Freyre e Cronjé a manutenção não apenas da supremacia masculina "branca", mas, igualmente, dos conteúdos civilizatórios dos quais os homens "brancos" são seus depositários, símbolos e propagadores: na obra de Freyre, a realização máxima do erotismo no encontro de dois seres libidinosos (o português e "mulata") e a possibilidade de mestiçagem (e "branqueamento" da nação) concomitantemente com afirmação do seu "poder de mando" no "patriarcalismo poligâmico"; em Cronjé, o desejo negado e escatológico, cujo impedimento e negação mantêm a endogamia "racial" e o controle social, político e econômico do patriarca bôer. Porém, um aspecto a mais merece destaque. A relação entre colonizador e colonizado "branco" e masculino é de ordem metonímica (cf. Moutinho, 2001). A alteridade "racial" está em vários textos do período representada no "negro", de modo que na hierarquia que preside qualquer tipo de mestiçagem ${ }^{24} \mathrm{O}$ vetor "branco" e masculino se sobrepõe ao "negro", mestiço e feminino, produzindo a "boa ordem" e a mistura "positiva", digamos assim. Na África do Sul, dá-se o oposto: no contato sexual "inter-racial" o elemento masculino e "branco" (isto sem falar no feminino), por ser concebido no interior de uma relação metafórica, sucumbe em uma percepção escatológica da "miscigenação".

\section{NOTAS}

1 As categorias de "cor" e "raça" estão grifadas com aspas. Sigo, com esse procedimento a sugestão de Fry (1996), sugundo a qual a noção de "raça" e seus termos correlatos devem, como outras categorias classificatórias, ser compreendidas como construções locais, históricas e culturalmente determinadas.

2 As principais leis estruturadoras do apartheid foram: a lei de Registro da População (Population Registration Act), que definia a população dos seguintes grupos "raciais": white, coloured e native; a Lei de Áreas de Grupo (Group Areas Act), que fixou as áreas residenciais com base na "raça", crian- 
do os chamados bairros étnicos. Ambas foram promulgadas em 1950. A terceira lei (datada de 1953) da Conservação das Diversões Separadas instituiu a separação espacial das categorias "raciais" em relação ao lazer, como, por exemplo, praia, piscina, banheiro público, teatro, cinema, ginásio de esportes, e ainda transportes, bibliotecas, entre outros (cf. Jonge, 1991). Isto sem contar com a Mixed Marriage Act de 1949 (a primeira lei do apartheid) e a Immorality Act de 1950, que proibiam as relações sexuais-afetivas "inter-raciais". A primeira tornou os casamentos "mistos" ilegais e a segunda criminalizou o intercurso carnal "inter-racial".

3 A ausência de "racismo" legalmente instituído na constituição republicana não exclui as hierarquias "raciais" e mesmo uma prática discriminatória de uma série de políticas estatais. Ver, nesse sentido, as análises de Giralda Seyfert (1996), Jair de Souza Ramos (1996); sobre o registro "racial" na polícia ver Olívia Cunha (1996); sobre crimes de honra, "raça" e moralidade, ver Sueann Caulfield (2000) e Rosane Lopes Corrêa (1994).

4 Sansone (1995) destaca, por exemplo, que no Brasil os casamentos "inter-raciais", os contatos com a polícia e o mercado de trabalho são áreas onde o preconceito racial é mais explicitado. Ver, nesse sentido, os trabalhos de Olívia Cunha (2001), do proprio Lívio Sansone (2001) e de Marcia Lima (2001).

5 As análises de Elza Berquó (1988), Nelson Valle e Silva (1987), entre outros, apontam, a partir do Censo do IBGE de 1980, para um aumento no número de pessoas classificadas como "pardas" na população brasileira, para a tendência homogâmica das uniões civil, religiosa, consensual e civil/religiosa no que tange às variáveis "cor", renda, educação e nível social e, finalmente, registram que não somente a porcentagem de casais "inter-raciais" se mantém em torno de $19 \%$ do total das uniões formais, como também há predominância de casais em que o homem aparece como o elemento "mais escuro" da união.

6 A literatura sobre o apartheid é bastante extensa, mas as obras selecionadas para a presente análise seguiram, primeiramente, um mapeamento que elaborei a partir dos trabalhos pioneiros de Fernando Rosa Ribeiro (1994, 1995) sobre o país. Os estudos citados circunscrevem-se em uma chave ana- lítica específica que veio, ao longo da década de 1990, relendo e questionando os antigos paradigmas interpretativos sobre o regime do apartheid. Ver, nesse sentido, as críticas de Coetzee (1991), de Hyslop (1995) e as análises de Fernando Rosa Ribeiro (1990, 1994, 1995, 1997).

7 De acordo com Coetzee (1991) e Fernando Rosa Ribeiro (1994, 1995) os escritos de Geoffrey Cronjé considerado o principal ideólogo do regime do apartheid - serviram de base para o Partido Nacionalista africâner na plataforma da campanha de 1948 e na posterior construção da política segregacionista do apartheid. Cronjé foi intelectual africâner que, de modo similar a Gilberto Freyre (embora com muito menos popularidade), concedeu forma e conteúdo a uma série de representações sociais sobre a alteridade "racial", que, entretanto, preexistiam aos seus escritos e se encontravam mais ou menos dispersos sobre o tecido social (cf. F. R. Ribeiro, 1994).

8 Na perspectiva do autor, as duas grandes correntes téoricas que dividiam a eugenia na Europa e nos Estados Unidos - neolamarkianos e mendelianos - foram interpretadas de modo peculiar na África do Sul. Nas suas palavras: "in practice, eugenic ideas were promoted and disseminated in a much looser fashion and with scant regard for theoretical inconsistencies. For this reason, neo-lamarckian and mendelian accounts for biological heredity frequently coexisted without apparent friction" (Dubow, 1995, p. 17).

9 Afirma Dubow: "Hysteria about the consequences of race mixture was to considerable extent supported by eugenic theory. This suggested that the offspring os racial 'crossing' suffered physical and moral degeneration as well as a decline in fertility" (1995, p. 183). Na concepção de Cronjé, ser coloured significa ter uma existência "deplorável", pois "the coloured consciousness is an intrinsically unhappy one" (Idem, p. 8). Além disso, sua convivência como os whites poderia vir a ameaçar a existência do afrikanervolk. Para Cronjé, a diferença "racial" simplesmente existe, e deve ser protegida para evitar o abastardamento (a "homogenização"): "a mishmash (mengelmoes) of races is something unnatural" (Coetzee, 1991, p. 9).

10 Também para Dubow, o "perigo negro" desempenhou um importante papel no vocabulário segregacionista da campanha eleitoral de 1929, e em 
uma geração posterior tal ameaça ajudou a consolidar o abstrato conceito de apartheid, o qual levou Malan ao poder em 1948.

11 A palavra-chave da perspectiva africâner acerca da miscigenação, expressa no pensamento de Cronjé, é mengelmoes, cuja tradução é "papa" - algo que indica um estado de indiferenciação. Na interpretação de Fernando Rosa Ribeiro (1994), a sociedade sul-africana concebida por Cronjé é, por natureza (e por vontade divina), uma coexistência de comunidades (volk) distintas, cuja indistinção resultaria em uma mengelmoes-samelewing. A conotação escatológica do termo é discutida por Coetzee (1991): mengel remete à mistura, confusão; moes é um termo culinário, mengelmoes é, nesse sentido, pejorativo - "significa uma mistura na qual não só o caráter individual, mas toda a estrutura original se perdeu; o que restou é uma papa disforme, indistinta - muito parecida a fezes, em realidade". Samelewing, ainda de acordo com a tradução de F. R. Ribeiro (1994), significa "sociedade", "comunidade" e "coabitação".

12 Dubow afirma que até a década de 1920 o termo "raça" era usado com referência à nação ("as in the British vs. Afrikaner race") (1995, p. 17) e, freqüentemente, remetido à metáfora do sangue. Nessa peculiar e complexa gama de referências, não é de estranhar a evidente dificuldade classificatória dos coloureds, categoria cuja impureza de sangue poderia passar despercebida, uma vez que não poderia ser depreendida da "aparência". Seguindo a análise de Verena Stolcke, entretanto, também se pode interpretar a preocupação com a pureza do sangue como o estabelecimento de um critério mais rígido de classificação "racial”, em contextos sociais onde houve um significativo processo de mestiçagem. Nas palavras da autora, a pureza do sangue "mientras que en España inicialmente se aplicó para distinguir a los cristianos viejos de los cristianos nuevos, en las colonias españolas fue adquiriendo gradualmente un nuevo significado. En este contexto se usa 'pureza de sangre' para distinguir entre los de origen africano/esclavo y los de origen libre/europeu" (1992, p. 123).

13 De acordo com a Wilcocks Commission, "the general obsevation of comparative physical inferiority cannot be ascribed to heredity or inferiror stock, unless it persists after environmental and nutritional di- ficiencies have been improved and brought up to the standard of the European race, with which a comparison is being made" (apud Dubow, 1995, p. 186).

14 Os britânicos venceram a segunda guerra AngloBôer (1899 a 1902) e criaram em 1910 a União SulAfricana. Nas décadas que se seguiram à derrota, os africâneres acabaram por desenvolver um nacionalismo ainda mais radical que o anterior. Como conseqüência, os negros criaram, em 1921, o Congresso Nacional Africano, a União dos Trabalhadores da Indústria e do Comércio, em 1919, e o movimento indiano conseguiu criar, em 1920, o Congresso Indiano Sul-Africano. O Partido Nacional, criado em 1914 pelo ex-general bôer Barry Hertzog, era considerado mais radical do que o Partido Sul-Africano, que governou o país até 1924, quando Hertzog e seu partido ganharam as eleições, tirando Jan Smuts e o PSA do poder. Hertzog, que contou nessa eleição com o apoio de mineiros "brancos", teve como principal plataforma o combate à pobreza branca, conseqüência da guerra Anglo-Bôer. Em 1934, o PSA e o Partido Nacional se juntaram, criando o Partido Unido. A aliança entre Hertzog e Jam Smuts foi desfeita em 1939, quando aquele se retirou do partido por conta de conflitos com Smuts, aliandose ao pastor calvinista Daniel Malan, no Partido Nacional Purificado (cf. Jonge, 1991).

15 Como pode ser observado na análise de Sueann Caufield, esse elementos - ainda que mobilizando diferentes sentidos e significados - aparecem como ameaças, ou mesmo inimigos de outros Estados-nação do período. No caso do Brasil, os valores capitalistas, individualistas, assim como a ameaça comunista e o anti-semitismo expresso nas políticas migratórias, foram vistos como um perigo para a homogeneidade "racial" da nação. As seguintes palavras de Caufield sintetizam de forma significativa certos contornos dessa "ameaça": "Alguns dos mais importantes movimentos negros de São Paulo, por exemplo, promoviam a idéia de que o Brasil era uma democracia racial culpando os imigrantes pela insistente discriminação racial" (Caufield, 2000, p. 277).

16 Para Cronjé, por exemplo, os coloureds representavam uma ameaça para o volk, porque poderiam passar por european. Coetzee sintetiza esse ponto com clareza: "the secret bastard who tries to find a place in the white community, and the bed of a white woman is [...] the sly stealer-in" (1991, p. 10). 
17 Para Cronjé, são condições sociais específicas que propiciam os casamentos "inter-raciais" e, para combatê-las, se fazia necessário criar uma legislação específica que impossibilitasse essas uniões. Os arquiinimigos do grande ideólogo do apartheid são o imperialismo britânico e o capitalismo. O primeiro os ameaça por conceder um estatuto igualitário aos africâneres e aos coloureds, e ambos os levaram à pobreza que, por sua vez, poderia levar ao descontrole social e à miscigenação (mishmash-society ou megelmoes-samelewing).

18 Sérgio Carrara em sua análise sobre o impacto social da luta contra a sífilis no Brasil do final do século XIX às primeiras décadas do século XX argumenta que a doença foi "um ponto de convergência de preocupações e interesses múltiplos: o interesse das autoridades policiais em moralizar e disciplinar o espaço público (a luta contra a prostituição, a pornografia, o álcool etc.); o das feministas na redicussão da condição feminina e dos papéis sexuais; o dos padres e pastores na salvação das almas de seus fiéis e na conservação da pureza moral" entre outros (1996, p. 16). Portanto, guardadas as diferenças locais, trata-se de um movimento que não parece ser exclusividade da África do Sul. Sueann Caulfield (2000), por exemplo, discute as campanhas e as políticas de "higiene moral" e a prostituição no Brasil das décadas de 1920 e 1930, que visavam a "moralizar" e "modernizar" a nação, controlando e regulamentando os espaços públicos e privados. Algo, inclusive, igualmente presente nas demais nações latino-americanas.

19 Para uma crítica sobre a questão "honra e vergonha" na sociedade mediterrânea, ver Stolcke (1992) e Caulfield (2000).

20 Ver, entre outros, Giberto Freyre (1977) e Paulo Prado (1931).

21 The Supreme Courts of Soth Africa, S.A. Law Reports, nov. 1950 (1).

22 Cf. também a análise de Caufield (2000) sobre os sentidos e os significados da "cor/raça" nas investigações policiais e nos julgamentos de conflitos sexuais nas décadas de 1920 e 1930).

23 Ver, por exemplo, Oliveira Vianna (1991, 1934).

24 Em verdade, a "mistura racial" nunca é representada exatamente como fusão; opera, seja positivamente (no branqueamento) ou negativamente (quando pensada como enegrecimento), algum tipo de hierarquia.

\section{BIBLIOGRAFIA}

ARAÚJO, Ricardo Benzaquen. (1994), Guerra e paz: Casa-grande \& senzala e a obra de Gilberto Freyre nos Anos 30. Rio de Janeiro, Editora 34.

BERQUÓ, Elza. (1998), "Sexualidade e demografia: comentários sobre a Exposição de Michel Bozon", in M. Loyola (org.), $A$ sexualidade nas ciências bumanas, Rio de Janeiro, Eduerj.

(1988), "Demografia da desigualdade". Novos Estudos (Cebrap), 21: 74-85.

CARRARA, Sérgio. (1996). Tributo a Vênus: a luta contra a sifilis no Brasil, da passagem do século aos anos 40. Rio de Janeiro, Fiocruz.

. (2004), "Estratégias anti-coloniais: sífilis, raça e identidade nacional no Brasil de Entre-guerras", in G. Hochmann e D. Armus (orgs.), Cuidar, controlar, curar: ensaios bistóricos sobre saúde e doença na América Latina e Caribe, Rio de Janeiro, Fiocruz, pp. 427-454.

CAUFIELD, Sueann. (2000), Em defesa da bonra: moralidade, modernidade e nação no Rio de Janeiro (1918-1940). Campinas, Unicamp/Centro de Pesquisa Social da Cultura.

CHALHOUB, Sidney. (1986), Trabalbo, lar e botequim: o cotidiano dos trabalhadores no Rio de Janeiro da Belle Époque. São Paulo, Brasiliense.

COETZEE, John M. (1999), Desonra. São Paulo, Companhia das Letras.

(1991), "The mind of apartheid: Geoffrey Cronjé, 1903”. Social Dynamics, 17 (1): 1-35, CT/SA, University of Cape Town. 
CORRÊA, Rosane L. (1994), A questão da cor no feminino: pretas, pardas e brancas nos inquéritos policiais nas freguesias de São Cristóvão e Espírito Santo. Dissertação de mestrado, Rio de Janeiro, PPGS/IFCS/UFRJ.

CRAPANZANO, Vincent. (1986), Waiting: the whites of South Africa. Londres, Paladin, Grafton Books.

CUNHA, Olívia M. Gomes da. (1996). "1933: um ano em que fizemos contato". Revista USP (Dossiê Povo Negro - 300 Anos), 28: 122-135.

. (2001), "Bondes do mal: notas sobre território, cor, violência e juventude em uma favela do subúrbio carioca", in C. B. Rezende e Y. Maggie (orgs.), Raça como retórica: a constituição da diferença, Rio de Janeiro, Civilização Brasileira.

DEGLER, Carl. (1976), Nem preto nem branco: escravidão e relações raciais no Brasil e nos Estados Unidos. Rio de Janeiro, Labor do Brasil.

DOUGlas, Mary. (1966), Pureza e perigo. São Paulo, Perspectiva.

DUBOW, Saul. (1995), Scientific racism in modern South Africa. Nova York, Cambridge University Press.

FREYRE, Gilberto. (1977), Casa-grande \& senzala. 18 ed. Rio de Janeiro, José Olympio.

FRY, Peter. (1991), "Politicamente correto em um lugar, incorreto noutro? (Relações raciais no Brasil e nos Estados Unidos, em Moçambique e no Zimbábue)". Estudos Afro-Asiáticos, 21: 167-177.

(1996), "O que a Cinderela negra tem a dizer sobre a "política racial no Brasil'". Revista da USP (Dossiê Povo Negro - 300 anos), 28: 122-135.

(2000), "Brazil: the burden of the past, the promise of the future". Daedalus, 129 (2).
FRY, Peter. \& CARRARA, Sérgio. (1986), "As vicissitudes do liberalismo no direito penal brasileiro". Revista Brasileira de Ciências Sociais, 2: 48-54.

GIACOMINI, Sônia M. (1994), "Beleza mulata e beleza negra. Estudos Feministas, 94: 217-227.

GOBINEAU, Joseph Arthur. (1937), Ensayo sobre la desigualdad de las razas humanas. Barcelona, Apolo.

GUIMARÃES, Antonio S. A. (1999), "Combatendo o racismo: Brasil, África do Sul e Estados Unidos". Revista Brasileira de Ciências Sociais, 39: 103-117.

HERINGER, Rosana. (1995), Nomos x hybris: reflexões sobre Gilberto Freyre e Geoffrey Cronjé. Rio de janeiro (mimeo.).

HYSLOP, Jonathan. (1995), "White working-class women and the invention of apartheid: 'purified' afrikaner nationalist agitation for legislation against 'mixed' marriages, 1934-1939”. Journal of African History, Cambrigde University Press.

JONGE, Klaas de. (1991), África do Sul: apartheid e resistência. São Paulo, Cortês/Eboh.

LIMA, Márcia. (2001), "Serviço de branco, serviço de preto": um estudo sobre cor e trabatho no Brasil urbano. Tese de doutorado, Rio de Janeiro, PPGSA/IFCS/UFRJ.

MAGGIE, Yvonne. (1992), Medo do feitiço: relações entre magia e poder no Brasil. Rio de Janeiro, Arquivo Nacional.

(1996), "Aqueles a quem foi negada a cor do dia: as categorias de cor e raça na cultura brasileira", in M. C. Maio e R. V. Santos (orgs.), Raça, ciência e sociedade, Rio de Janeiro, CCBB/Fiocruz.

MOUTINHO, Laura. (2001), Razão, "cor" e desejo: uma análise comparativa sobre relacionamentos afetivo-sexuais 'inter-raciais' no Brasil e na África do Sul. Tese de doutorado, Rio de Janeiro, PPGSA/IFCS/UFRJ. 
PRADO, Paulo. (1931), Retratos do Brasil: ensaios sobre a tristeza brasileira. 3 ed. Rio de Janeiro, F. Briguiet e Cia.

RAMOS, Jair de Souza. (1996), "Dos males que vêm com o sangue: as representações raciais e a categoria do imigrante indesejável nas concepções sobre imigração da década de 20", in M. C. Maio e R. V. Santos (orgs.), Raça, ciência e sociedade, Rio de Janeiro, CCBB/Fiocruz.

RIBEIRO, Carlos A. Costa. (1995), Cor e criminalidade: estudo e análise da justiça no Rio de Janeiro (1900-1930). Rio de Janeiro, Editora da UFRJ.

RIBEIRO, Fernando Rosa. (1990). Apartheid: o reino de Deus na terra. Dissertação de mestrado, Brasília, UnB.

(1994). "A construção da nação na África do Sul: a ideologia individualista e o apartheid". Série Estudos Ciências Sociais, 3, PPGS/LPS/IFCS/UFRJ.

(1995), Apartheid e democracia racial: South Africa and Brazil in contrast. Tese de doutorado, Universidade de Utrecht.

(1997), "Ideologia nacional, antropologia e "questão racial"'. Estudos AfroAsiáticos, 31.

SANSONE, Lívio. (1995), "As relações raciais em Casa-grande E senzala revistas à luz do processo de internacionalização e globalização", in M. C. Maio e R. V. Santos (orgs.), Raça, ciência e sociedade, Rio de Janeiro, CCBB/Fiocruz.

(2001), "Não trabalho, consumo e identidade negra: uma comparação entre Rio e Salvador", in C. B. Rezende e Y. Maggie (orgs.), Raça como retórica: $a$ constituição da diferença, Rio de Janeiro, Civilização Brasileira.

SILVA, Nelson do Valle. (1987), "Distância social e casamento inter-racial no Brasil". Estudos Afro-Asiáticos, 14: 54-84.
(1991), "Estabilidade temporal e diferenças raciais no casamento inter-racial”. Estudos Afro-Asiáticos, 21: 49-60.

SEYFERTH, Giralda. (1985), "A antropologia e a teoria do branqueamento da raça no Brasil: a tese do João Batista de Lacerda". Revista do Museu Paulista, 30.

(1996), "Construindo a nação: hierarquias raciais e o papel do racismo na política de imigração e colonização", in M. C. Maio e R. V. Santos (orgs.), Raça, ciência e sociedade, Rio de Janeiro, $\mathrm{CCBB} /$ Fiocruz.

STOLCKE, Verena. (1992), Racismo y sexualidad en la Cuba colonial. Madrid, Alianza Editorial.

VIANNA, Oliveira. (1934), Raça e assimilação. São Paulo, Cia. Editora Nacional.

(1956), A evolução do povo brasileiro. Rio de Janeiro, José Olympio.

(1991), "O tipo brasileiro e seus elementos formadores", in _ Ensaios Inéditos/Oliveira Vianna, Campinas, Editora da Unicamp.

WADE, Peter. (1993), Blackness and race mixture: the dynamics of racial identity in $\mathrm{Co}$ lombia. Baltimore, The Johns Hopkins University Press.

(2000), "Identidade racial, formação do Estado e nacionalismo: uma visão teórica". Revista Interseções, 2 (1), UERJ/Nape. 
CONDENADOS PELO DESEJO? RAZÕES DE ESTADO NA ÁFRICA DO SUL

Laura Moutinho

\section{Palavras-chave}

Raça e sexualidade; Gênero e raça; Raça, direito e sexualidade; Erotismo; Raça, nação e sexualidade.

O objetivo deste artigo é analisar a inter-relação entre "raça", gênero e desejo erótico "inter-racial" na África do Sul, a partir do estudo de alguns casos enquadrados na Immorality Act - lei que proibia o intercurso carnal "inter-racial" na era do apartheid. Na África do Sul os relacionamentos afetivo-sexuais "inter-raciais" foram regulados (e organizados) explicitamente por uma legislação específica, constituída sob a lógica de uma razão de Estado. Meu objetivo é ajustar o foco para a percepção de "raça" que preside esse empreendimento, assim como dar visibilidade à importância das assimetrias de gênero e do desejo erótico "inter-racial", que surgem no centro do palco das proibições fundantes do regime do apartheid. Olhar contrastivamente para a África do Sul permitirá, ao final da análise, entrever alguns pontos cegos da ideologia brasileira no que tange às questão relativas à "raça", ao gênero e à sexualidade.
CONDAMNÉS PAR LE DÉSIR? RAISONS D'ÉTAT EN AFRIQUE DU SUD

Laura Moutinho

\section{Mots-clés}

Race et sexualité; Genre et race; Race, droit et sexualité; Érotisme; Race, nation et sexualité.

L'objectif de cet article est d'analyser, à partir de l'étude de certains cas encadrés dans l'Immorality Act - une loi qui interdisait les relations sexuelles "interraciales" à l'époque de l'apartheid, la relation entre la "race", le genre et le désir érotique "interracial" en Afrique du Sud. Dans ce pays, les rapports affectifs et sexuels "interraciaux" ont été réglementés (et organisés) par une législation spécifique, mise au point sous la logique d'une raison d'État. Notre but est d'ajuster la mise au point vers la perception de "race" qui préside cette entreprise, ainsi que de rendre visible l'importance des asymétries de genre et de désir érotique "interracial", qui surgit au centre de la scène des prohibitions qui servent de fondement au régime de l'apartheid. Un regard contrasté vers l'Afrique du Sud permettra, en conclusion, d'entrevoir certains points de l'idéologie brésilienne qui échappent à notre perception en ce qui concerne les questions relatives à la "race", au genre et à la sexualité.

\section{CONDEMNED BY DESIRE? REASONS OF STATE IN SOUTH AFRICA}

Laura Moutinho

\section{Keywords}

Race and sexuality; Gender and race; Race, rights and sexuality; Eroticism; Race, nation, and sexuality.

This paper aims at analyzing the inter-relation among race, gender, and inter-racial erotic desire in South Africa, based on the study of some cases fitted in the Immorality Act - the law that prohibited inter-racial carnal intercourse in the apartheid era. In South Africa, inter-racial sexualaffective relationships were regulated (and organized) explicitly by a specific legislation, built under the logics of reason of state. Our objective is to adjust the focus to the perception of race that presides such entrepreneurship and to give visibility to the importance of asymmetries of gender and inter-racial erotic desire that appeared in the core of the establishing prohibitions in the apartheid regimen. A contrasting sight on South Africa makes it possible, in the end of the analysis, indistinctly see some blind spots in the Brazilian ideology concerning race, gender, and sexuality. 